\title{
TUÂN THỦ CHĂM SÓC DỰ PHÒNG VIÊM PHỔI THỞ MÁY CỦA NHÂN VIÊN Y TẾ TẠI MộT BỆNH VIỆN ĐA KHOA TƯ NHÂN, 2020
}

\section{TÓM TẮT}

Viêm phổi liên quan đến thở máy là viêm phổi bệnh viện xuất hiện sau khi người bệnh có đặt ống nội khí quản trên 48 giờ và thông khí nhân tạo. Đối vớ các bênh nhân thở máy, viêm phổi làm kéo dài thời gian điều trị, tăng nguy cơ tử vong. Nghiên cứu được thực hiện với mục tiêu tìm hiểu thực trạng tuân thủ chăm sóc dự phòng viêm phổi thở máy của nhân viên y tế tại một bệnh viện đa khoa tư nhân. Nghiên cứu được thiết kế theo thiết kế nghiên cứu mô tả cắt ngang, kết hợp định lượng và đinh tính được tiến hành tại khoa ICU của bệnh viện trên 25 NVYT gồm có 17 Điều dưỡng chăm sóc và 08 Bác sỹ điều tri thực hiện gói chăm sóc dự phòng VAP. Kết quả cho thấy tỉ lệ tuân thủ gói chăm sóc dự phòng VAP của NVYT gồm bác sỹ điều trị và điều dưỡng chăm sóc tại Khoa ICU bệnh viện lần lượt là: $100 \%$ và $89,1 \%$. Hai bước kỹ thuật trong gói dự phòng VAP mà điều dưỡng chăm sóc chưa tuân thủ cụ thể: Đặt đâuu cao người bệnh $30^{\circ}-45^{\circ}$; vệ sinh răng miệng hàng ngày với chlorhexidine $0,12 \%$ lần lượt là $93,9 \%$ và $95,2 \%$. Nghiên cứu khuyến nghị bệnh viện và khoa ICU giám sát chặt chẽ các bước có tỷ lệ tuân thủ thấp là đặt đâu người bệnh cao $30^{0}-45^{0}$ và vệ sinh răng miệng hàng ngày với chlorhexidine $0,12 \%$

Tư khoá: tuân thủ, viêm phổi thở máy, chăm sóc, nhân viên y tế, bệnh viện

\section{SUMMARY \\ COMPLIANCE AMONG HEALTH WORKERS ON PNEUMONOSIS PREVENTIVE PROCEDURE FOR PATIENTS HAVING ENDOTRACHEAL INTUBATIONAT A PRIVATE HOSPITAL, 2020}

Pneumonosis related with ventilator is pneumonosis after patient having endotracheal intubation for more than 48 hours. This kind of pneumonosis might make treatment last longer and increase the risk of mortality. This study aimed to investigate the compliance with treatment and caring procedure among health workers at a private hospital. The study design was cross sectional design using quantitative and qualitative methods at ICU department of the hospital with participation of 8 doctors and 17 who actively assigned to provide medical care for patients using ventilator. Results show that the prevalence of health workers who complied with procedure was $100 \%$ among doctors

*Trường Đại họ Y tế công cộng

Chịu trách nhiệm chính: Nguyễn Ngọc Bích

Email: nnb@huph.edu.vn

Ngày nhận bài: 9.4.2021

Ngày phản biên khoa học: 25.5.2021

Ngày duyệt bài: 9.6.2021

\section{Nguyễn Ngọc Bích*, Đoàn Minh Sang*}

and $89.1 \%$ among nurses. Two elements which had lowest prevalence of compliance were putting patients'head high $30^{0}-45^{\circ}$; and dental care with chlorhexidine $0,12 \%$, compliant prevalences were $93.9 \%$ and $95 ., 2 \%$. It was recommended that the hospital and ICU department should provide more supervision on patient's care especially for two elements of the procedure above

Keywords: compliance, pneumonosis, ventolator, patient's care, health workers, hospital

\section{I. ĐĂTT VẤN ĐỀ}

Viêm phổi liên quan đến thở máy (VAP) là viêm phổi bệnh viện xuất hiện sau khi người bênh (NB) có đă̆t ống nôii khí quản trên 48 giờ và thông khí nhân tạo[1]. Tại Mỹ, VAP chiếm tỉ lệ từ $25-42 \%$ các trường hợp nhiễm khuẩn thường găp tai các khoa Hồi sức tích cực (ICU) [7]. Tại Viêt Nam, tỉ lê VAP đặc biệt cao trong nhóm NB điểu trị tại khoa ICU $43-63.5 / 1000$ ngày thơ máy [1]. VAP kéo dài thời gian thở máy từ 7.6 đến 11.5 ngày và kéo dài thời gian nằm viện từ 11.5 đến 13.1 ngày chi phí điều trị cũng từ đó mà tăng lên - ước tính khoảng 40.000 USD cho mỗi NB [9] và Tî lệ tử vong ở các NB có VAP là $46 \%$ [8] so với nhóm NB tương tự không có VAP. Vì vậy, công việc phòng ngừa VAP được cho là công việc ưu tiên hàng đầu trong chăm sóc các bệnh nhân nặng.

Năm 2001,Viên cải tiến y tễ (Institute for Healthcare Improvement - IHI) giới thiệu gói thơ máy hay còn gọi là gói chăm sóc dự phòng viêm phổi liên quan đến thở máy (VAP bundle) bao gồm 4 can thiệp y tế: đầu cao $30^{\circ}-45^{\circ}$ nếu không có chống chỉ định; đánh giá an thần - cai thở máy hàng ngày; phòng ngừa loét dạ dày; phòng ngừa huyết khối tĩnh mạch sâu được nhiều khoa ICU của các bệnh viện trên thế giới áp dụng và kết quả tỉ lệ VAP đã giảm đáng kể. Năm 2010, IHI đưa thêm 01 can thiệp y tế - vệ sinh răng miệng hàng ngày bằng Chlorhexidine. Dựa trên báo cáo của nhiều bệnh viện áp dụng gói VAP bundle của IHI khuyến cáo cho thấy tỉ lệ VAP giảm trung bình khoảng 45\% [8]. Nghiên cứu được thực hiên nhằm xác đinh những tuân thủ, những kiến thức hiểu biết về gói dự phòng VAP trong công tác điều trị và chăm sóc của NVYT tại bênh viện và hay ghi nhận những thao tác thực hiện kỹ thuật đúng, đầy đủ và các yếu tố ảnh hưởng đến sự tuân thủ này như thế nào lên NB có thở máy tại Khoa ICU. 


\section{II. ĐỐI TƯỢNG VÀ PHƯƠNG PHÁP NGHIÊN CỨU \\ 2.1. Đối tượng nghiên cứu: \\ 2.1.1. Đối tượng nghiên cứu định lượng:}

- Là Bác sỹ và Điều dưỡng tham gia trực tiếp điều trị và chăm sóc gói dự phòng VAP cho NB tai khoa ICU.

- Là người bênh nằm điều trị tại khoa ICU được các NVYT này thực hiện các thao tác kỹ thuật điểu trị và chăm sóc trong gói dự phòng VAP

\subsection{2. Đối tướng nghiên cứu đỉnh tính}

- Lãnh đạo bệnh viện, Trưởng phòng Quản lý chất lượng, Trưởng Phòng Kiểm soát nhiễm khuẩn, Điều dưỡng trưởng, BS điêuu trị, Điều dưỡng viên công tác tại Khoa ICU của bệnh viện

\subsection{Thời gian và địa điểm nghiên cứu}

- Thời gian nghiên cứu: từ tháng 4/2020 đến tháng 08/2020.

- Địa điểm nghiên cứu: tại khoa ICU, một bệnh viện đa khoa tư nhân phía Nam

2.3. Thiết kế nghiên cứu: Nghiên cứu được thiết kế là nghiên cứu mô tả cắt ngang, bảng kiểm định lương thu thâp những thông tin mô tả thực trạng tuân thủ trên lượt thực hiện gói chăm sóc dự phòng viêm phổi của Bác sỹ, Điều dưỡng tại khoa ICU

2.4. Cõ̃ mẫu nghiên cứu

2.4.1. Cỡ mầu nghiên cứu định lượng:

Nghiên cứu sử dụng công thức tính cỡ mẫu ước lượng 01 tỷ lệ

$$
\mathrm{n}=\frac{\mathrm{Z}^{2}{ }_{1-\alpha / 2} \mathrm{P}(1-\mathrm{P})}{\mathrm{d}^{2}}
$$

Trong đó:

- n là cỡ mẫu tối thiểu cho nghiên cứu

- Z 21 - a/2: 1,96 (với $\alpha=0.05$ )

- $p$ là tỉ lệ tuân thủ của NVYT trong việc áp dụng gói chăm sóc dự phòng viêm phổi (chọn $p$ $=0.25$ theo nghiên cứu của tác giả Đặng Thị Vân Trang (2011) về Khảo sát mức độ tuân thủ thực hành phòng ngừa viêm phổi liên quan thở máy tại các khoa săn sóc đặc biệt Bệnh viện Chợ Rẫy)[6]

- d là độ chính xác mong muốn ( $\mathrm{d}=0.05)$

- cõ mẫu: $n=1.96 *\left((0.25 * 0.75) / 0.05^{2}\right)=$ 147 lượt chăm sóc của NVYT đã được lưa chon cho nghiên cứu này. 4 phỏng vấn sâu và 2 thảo luận nhóm đã được thực hiện

\subsection{Phương pháp chọn mẫu:}

- Lựa chon các lượt điều trị và chăm sóc của NVYT là bác sỹ và điều dưỡng tham gia thực hiện gói chăm sóc dự phòng VAP cho NB có thở máy tai khoa ICU.

- Đối với người bệnh áp dụng chọn mẫu chủ đích là những NB thở máy được áp dụng gói chăm sóc dự phòng VAP, số máy thở hiện có là 05 máy và số giường bệnh có là 08 giường. Vì vậy, số NB thở máy tại khoa ICU điều được lựa chọn giám sát, trừ khi NB tử vong trong vòng 48 giờ sau khi được đặt nội khí quản thở máy.

- Hoạt động thực hiện lượt điều trị và chăm sóc của NVYT trên NB thở máy qua hai kíp trực: kíp trực 1 từ 07h30 - 19h30; kíp trực 2 từ 19 h30 $-07 h 30$.

- Phương pháp: quan sát trực tiếp, ghi nhận qua bảng kiểm được xây dựng và phát hành với mã văn bản VM- ICU VAP Bundle 2019.

- Công cụ: bảng kiểm phòng ngừa viêm phổi liên quan đến thở máy

\subsection{Phương pháp thu thập số liệu:}

- Công cư thu thập số liệu:

- Bảng câu hỏi cấu trúc thông tin NVYT và kiến thức, đặc điểm công việc

○ Bảng kiểm đánh giá thực hành chăm sóc gói VAP

- Quá trình thu thập số liệu được thực hiện theo 02 bước:

Bước 1: Quan sát thực hành các biện pháp dự phòng VAP tại khoa ICU. Nghiên cứu viên gặp Bác sỹ trưởng khoa, điều dưỡng trưởng thông báo mục đích nghiên cứu, kế hoạch, thời gian nghiên cứu tại khoa ICU. Trong khoảng thời gian từ tháng 4 đến tháng $8 / 2020$ sẽ có giám sát quá trình lượt thực hiện gói chăm sóc dư phòng VAP cho người bênh có thở máy bao gồm: Bác sỹ điều trị,, Điều dưỡng chăm sóc nhưng các nhân viên y tế này không được biết có giám sát. Sau khi được sự đồng ý của lãnh đạo khoa thì sẽ tiến hành giám sát.

Bước 2: Khảo sát các thông tin cá nhân đến sự tuân thủ thực hiện gói dự phòng VAP. Sau khi NCV giám sát xong sẽ tiến hành phát vấn khảo sát về các yếu tố gây ảnh hưởng đến sự tuân thủ và nhân khẩu học của ĐTNC. Sau mỗi ca làm việc BS, ĐD Khoa ICU sẽ tập trung tại phòng giao ban của khoa ICU để trả lời bộ câu hỏi theo phương pháp phát vấn.

2.7. Các biến số trong nghiên cứu: Biến số nghiên cứu gồm các nhóm sau đây

Nhóm biến số về thực hành gói chăm sóc VAP của NVYT: 05 bước kỹ thuật trong gói dự phòng VAP.

Nhóm biến số về nhân khẩu học: tuổi, giới tính, trình độ chuyên môn, thâm niên công tác, nghề nghiệp

Nhóm biến số về kiến thức hiểu biết gói chăm sóc dự phòng VAP: các định nghĩa, các biện pháp phòng ngừa, ý nghĩa từng bước kỹ thuật...

Nhóm biến số về môi trường làm việc: số buổi trực trung bình của NVYT, số người bênh trung bình được phân chăm sóc, quá tải cồng 
việc, sự phối hợp của NVYT trong điều trị và chăm sóc, cung cấp trang thiết bị...

2.8. Phương pháp phân tích số liệu. Sử dụng phần mềm SPSS 20.0 để phân tích số liệu sau khi được nhập vào Epidata

Số liệu định tính được gõ băng và phân tích theo chủ đề về yếu tố ảnh hưởng

2.9. Đạo đức trong nghiên cứu. Đề tài nghiên cứu được trình đến Ban Giám đốc phê duyệt và trình đến Trưởng khoa ICU và Điều dưỡng trưởng ICU. Nghiên cứu đã được hội đồng đạo đức trường $\mathrm{DH}$ YTCC thông qua theo quyết định số: 237/2020/YTCC-HD3 ngày 04/06/2020

\section{KẾT QUẢ NGHIÊN CỨU}

3.1. Thực trạng tuân thủ thực hiện gói chăm sóc dự phòng VAP của Bác sỹ̃, Điêuu dưỡng tại Khoa ICU. Một số thông tin chung về đặc điểm cá nhân của đối tượng nghiên cứu gồm: Nhân viên y tế và người bệnh được thực hiện gói chăm sóc dự phòng VAP

Bảng 3.1. Thồng tîn chung của nhân viên y tế( $N=25)$

\begin{tabular}{|c|c|c|}
\hline Nội dung & Số lượng & Tỷ lệ (\%) \\
\hline Giới tính: Nam & 13 & 52 \\
\hline Nữ & 12 & 48 \\
\hline Tuối: $\leq 34$ tuổi & 13 & 52 \\
\hline 35-44 tuổi & 8 & 32 \\
\hline 245 tuối & 4 & 16 \\
\hline \multicolumn{3}{|c|}{ Bằng cấp chuyên môn } \\
\hline Trung cấp & 1 & 4 \\
\hline Cao đằng & 3 & 12 \\
\hline Đại học trở lên & 21 & 84 \\
\hline \multicolumn{3}{|l|}{ Thâm niền công tác } \\
\hline$\leq 5$ năm & 6 & 24 \\
\hline
\end{tabular}

\begin{tabular}{|c|c|c|}
\hline $6-9$ năm & 7 & 28 \\
\hline$\geq 10$ năm & 12 & 48 \\
\hline
\end{tabular}

Trong 25 NVYT tham gia nghiên cứu gồm: 08 Bác sỹ và 17 Điều dưỡng có tỷ lệ nam, nữ gần bằng nhau (nam chiếm $52 \%$ và nữ chiếm $48 \%$ ). Đô tuổi trong nhóm NVYT này có tuổi đời trẻ và nẳm trong nhóm độ tuổi $\leq 34$ tuổi $(52 \%)$. Về bằng cấp chuyên môn thì tất cả NVYT trong nhóm nghiên cứu đều có từ đại học trở lên $(84 \%)$ và chỉ có một NVYT có trình độ trung cấp (4\%), số năm kinh nghiệm $\geq 10$ năm (48\%). Đây là những lợi thế mà khoa ICU có được, vì tất cả NVYT cần có sự nhận thức về vấn đề tốt cũng như kiến thức dựa trên bằng cấp được đào tạo để tuân thủ thực hành tốt nhất. Việc NVYT trao dồi học tập đạt bằng cấp cao, kinh nghiệm nhiêu năm trong thực hành đúng chuyên môn sẽ giúp nâng cao thái độ tốt trong công việc.

Bảng 3.2. Thực trạng số lượt tuân thủ của NVYT (N = 147 /ượt/ 7 Người bệnh)

\begin{tabular}{|c|c|c|c|}
\hline \multicolumn{2}{|c|}{ Đặc điểm } & $\begin{array}{c}\text { Số lượt tuân } \\
\text { thử / tổng số } \\
\text { lượt giám sát }\end{array}$ & $\begin{array}{c}\text { Tỷ lệ } \\
\text { (\%) }\end{array}$ \\
\hline Bác sỹ & Tuân thủ & 147 & 100 \\
\hline $\begin{array}{c}\text { Điều } \\
\text { dưỡng }\end{array}$ & Tuân thủ & 131 & 89.1 \\
\hline
\end{tabular}

Bảng 3.2 Thực trạng số lượt tuân thủ thực hiện gói chăm sóc dự phòng VAP của NVYT lển NB thở máy tại khoa ICU cho thấy rằng ở nhóm bác sỹ và điều dưỡng có sự khác biệt trong tuân thủ. Nhóm bác sỹ đạt $(100 \%)$ chỉ định ra các bước điều trị trong gói dự phòng VAP cho NB thì nhóm điều dưỡng đat (89.1\%), nhìn vào biểu đồ 3.1 cho thấy rõ số lượt tuân thủ thực hiện và không tuân thủ thực hiện của nhóm điều dưỡng.

Bảng 3.3. Thực trạng tuân thủ thực hiện của NVYT về số lượt trong gói chăm sóc dự phòng VAP tại Khoa ICU ( $N=147)$

\begin{tabular}{|c|l|c|c|}
\hline \multicolumn{2}{|c|}{ Đặc điểm } & $\begin{array}{c}\text { Số lượt tuân thủ/ tống số } \\
\text { lượt giám sát (N = 147) }\end{array}$ & $\begin{array}{c}\text { Tỷ lệ } \\
\mathbf{( \% )}\end{array}$ \\
\hline Đặt đầu người bệnh cao cho người bệnh 30-450 & Tuân thủ & 138 & 93.9 \\
\hline Vệ sinh răng miệng 8h/lần bằng Chlorhexidine & Tuân thủ & 140 & 95.2 \\
\hline Đánh giá an thần cai thở máy & Tuân thủ & 147 & 100 \\
\hline Phòng viêm loét dạ dày & Tuân thủ & 147 & 100 \\
\hline Phòng ngừa huyểt khổi tînh mạch sâu & Tuân thủ & 147 & 100 \\
\hline
\end{tabular}

Bảng 3.3 cho thấy số lượt tuân thủ của nhóm điều dưỡng chỉ đạt 138 lượt ở bước cho người bệnh nằm đầu cao $30-45^{\circ}(93.9 \%)$, và 140 lượt ở bước Vệ sinh răng miệng $8 \mathrm{~h} /$ lần bằng Chlorhexidine (95.2\%) như vậy tổng số lượt chưa tuân thủ hai bước kỹ thuật này của nhóm điêu dưỡng có 16 lượt (10.9\%). Mặc dù vậy, khảo sát viên cũng có ghi nhận chia sẻ trong buổi TLN: "Chúng em luôn gặp khó khăn với những NB béo phì, thể trạng to vì khi cho nằm đầu cao đầu giường $30-45^{\circ}$ thì vài phút sau NB tự tuột xuống nên không còn chính xác độ cao của đầu giường. Vì vậy, phải luôn quan sát và hỗ trợ lại tư thế "Một thành viên khác chia sẻ: "Tua trực đêm thường ít nhân lực hơn tua ngày mà NB nhập viện thường hay vào buổi tối từ cấp cứu, dẫn đến đôi lúc chưa tuân thủ đủ kịp thời trong chăm sóc NB". (TLN 2) 
VIETNAM MEDICAL JOURNAL N²0 - JUNE - 2021

Bảng 3.4. Kiến thức về gói dự phòng VAP tại BÊNH VIÊNN

\begin{tabular}{|c|c|c|c|}
\hline \multicolumn{2}{|l|}{ Đặc điếm } & Tân suất & Tỷ lệ (\%) \\
\hline \multirow{2}{*}{ Đặt đâu người bệnh cao cho người bệnh $30-45^{0}$} & Trả lời Đúng & 25 & 100 \\
\hline & Trả lời Sai & & \\
\hline \multirow{2}{*}{ Tác dụng của đặt cao đầu giường người bệnh là gì? } & Trả lời Đúng & 23 & 92 \\
\hline & Trả lời Sai & 2 & 8 \\
\hline \multirow{2}{*}{ Vệ sinh răng miệng hàng ngày bằng dung dịch gì? } & Trả lời Đúng & 25 & 100 \\
\hline & Trả lời Sai & 0 & 0 \\
\hline \multirow{2}{*}{ Tác dụng vệ sinh răng miệng là gì? } & Trả lời Đúng & 21 & 84 \\
\hline & Trả lời Sai & 4 & 16 \\
\hline \multirow{2}{*}{$\begin{array}{c}\text { Tác dụng hàng ngày ngừng an thần, đánh giá khả năng } \\
\text { sằn sàng rút nội khí quản là gì? }\end{array}$} & Trả lời Đúng & 20 & 80 \\
\hline & Trả lời Sai & 5 & 20 \\
\hline \multirow{2}{*}{ Tác dụng dự phòng loét dạ dày là gì? } & Trả lời Đúng & 22 & 88 \\
\hline & Trả lời Sai & 3 & 12 \\
\hline \multirow{2}{*}{ Thực hiện dự phòng loét dạ dày như thế nào? } & Trả lời Đúng & 25 & 100 \\
\hline & Trả lời Sai & 0 & 0 \\
\hline \multirow{2}{*}{ Tác dụng dự phòng huyết khối tĩnh mạch sâu là gì? } & Trả lời Đúng & 21 & 84 \\
\hline & Trả lời Sai & 4 & 16 \\
\hline \multirow{2}{*}{$\begin{array}{c}\text { Thực hiện dự phòng huyết khối tĩnh mạch sâu như thế } \\
\text { nào? }\end{array}$} & Trả lời Đúng & 25 & 100 \\
\hline & Trả lời Sai & 0 & 0 \\
\hline
\end{tabular}

Qua bảng 3.4 cho thấy kết quả về kiến thức gói dự phòng VAP của 25 NVYT tại khoa ICU đều đạt $(100 \%)$ chọn đúng các bước trong gói dự phòng VAP, tuy nhiên tác dụng của từng bước này thì lại không đạt như: Tác dụng của đặt cao đầu giường người bệnh (92\%), Tác dụng vệ sinh răng miệng (84\%), Tác dụng hàng ngày ngừng an thần, đánh giá khả năng sẵn sàng rút nội khí quản $(80 \%)$, Tác dụng dự phòng loét dạ dày (88\%), Tác dụng dự phòng huyết khối tĩnh mạch sâu $(84 \%)$. Với kết quả này cho thấy, phưởng pháp đào tạo rất quan trọng, lựa chọn phương pháp nào để giúp NVYT vừa nắm chắt về lý thuyết để hiểu được tác dụng của từng bước kỹ thuật cũng giúp sự thay đổi tính tuân thủ trong thực hành của NVYT. Vì vậy, kết quả này đã chứng minh cho sự tương đồng về kết quả phương pháp đào tạo chuyên môn có $20 \%$ NVYT chỉ tham gia đào tạo thực hành và qua khảo sát về kiến thức gói dự phòng VAP tại bệnh viện các kiến thức về tác dụng của từng bước này trả lời sai từ $08-20 \%$. Vì vậy, những NVYT được đào tạo cả lý thuyết và thực hành sẽ nắm chắt hơn kiến thức chăm sóc NB và tác dụng của từng kỹ thuật trong chăm sóc gói dự phòng VAP.

\section{BÀN LUẬN}

Qua khảo sát cho thấy thực trạng tuân thủ thực hiện của NVYT về gói chăm sóc dự phòng VAP tại khoa ICU BV BỆNH VIỆNcó tỉ lệ tuân thủ các bước kỹ thuật trong gói chăm sóc dự phòng VAP: Đánh giá an thần cai máy thở, phòng viêm loét da dày, phòng ngừa huyết khối tĩnh mạch sâu đạt tuân thủ $100 \%$, tỉ lệ tuân thủ ở 02 bước còn lại trong gói dự phòng là đặt đầu người bệnh cao $30-45^{\circ}$ và vệ sinh răng miệng lần lượt đạt $93,9 \%$ và $95,2 \%$, kết quả này so với tỉ lệ tuân thủ đặt đầu người bệnh cao $30-45^{\circ}$ tỉ lệ này thấp hơn so với nghiên cứu của tác giả Đặng Thị Vân Trang (2011) là 96,5\% [6]. Các nghiên cứu cũng đã chứng minh rằng việc đặt cao đầu giường là một phần không thể thiếu của gói dự phòng VAP và liên quan đến việc giảm tỉ lệ viêm phổi liên quan thở máy. Tác giả Mitra $B$ Drakulovic MD đã tiến hành nghiên cứu cho kết quả tỉ lệ viêm phở thở máy ở bệnh nhân có chỉ định đắt cao đầu giường giảm còn $8 \%$ so với $34 \%$ những bệnh nhân không có chỉ định và có liên quan ảnh hưởng đến chăm sóc dinh dưỡng của người bệnh nằm ngửa là $50 \%$, hệ thống thông khí của cơ thể người bênh được cải thiện hơn [43]. Kết quả về Vệ sinh răng miệng hàng ngày với chlorhexidine $0,12 \%$ đạt $95,2 \%$ cũng thấp hơn so với nghiên cứu của tác giả Đặng Thị Vân Trang (2011) 98,8\% [6]. Xét về từng bước trong gói chăm sóc dự phòng VAP thì bài nghiên cứu của tác giả Đặng Thị Vân Trang (2011) thực hiện nghiên cứu tại BV Chợ Rẫy đạt tuân thủ cao hởn nhưng về đối tượng nghiên cứu là điều dưỡng chăm sóc tại khoa hồi sức cấp cứu, và một số khoa lâm sàng khác, thì tỉ lệ tuân thủ thực hành đúng các bước trong gói dự phòng trọn cho một NB rất thấp $(24,8 \%)$ [6] so với tỉ lệ tuân thủ của điều dưỡng thực hiện gói chăm sóc dự phòng của NCV thì đạt $(89,1 \%)$ Dựa trên các kết quả này cho thấy tỉ lệ điều dương tuân thủ các bước trong gói chăm sóc dự phòng viêm 
phổi thở máy tại bệnh viện tuy chỉ đạt 89,1\% nhưng đã là khá cao.

\section{KẾT LUẬN}

Tỉ lệ tuẩn thủ thực hiện gói chăm sóc phòng ngừa VAP của nhóm Bác sỹ đạt $100 \%$ và nhóm Điều dưỡng đạt $89.1 \%$ và tỉ lệ chưa tuân thủ ở 02 bước kỹ thuật trong gói dự phòng là đặt đầu người bệnh cao $30-45^{\circ}$ và vệ sinh răng miệng lần lượt đạt 93,9\% và 95,2\%.

\section{TÀI LIÊU THAM KHẢO}

1. Bộ Y Tế, "Hướng dẫn phòng ngừa viêm phổi bệnh viện trong các cơ sở khám bênh, chữa bệnh (B̉an hành kèm theo Quyêt định số: 3671/QĐ-BYT ngày 27 tháng 9 năm 2012 của Bộ Y tê)," "Tháng 92012.

2. Đăng Thị Vân Trang (2011), "Thực hiện khảo sát mức độ tuân thủ thực hành phòng ngửa viêm phổi liên quan thở maáy tại các đơn vị săn sóc đặc biêt bênh viên Chợ Rẫy"

3. Walkey $\mathrm{Aj}^{\mathrm{j}}$ et al (2009), "Epidemiology of ventilator-associated pneumonia in a long-term acute care hospital.," Infect Control Hosp Epidemiol, pp. (4):319-24.

4 J. o. R. a. C. C. Medicine (2006), "Guidelines for the Management of Adults with Hospitalacquired, Ventilator-associated, and Healthcareassociated Pneumonia," pp. 388-416.

5 Muscedere JG et al (2010), "Mortality, attributable mortality, and clinical events as end points for clinical trials of ventilator-associated pneumonia and hospital-acquired pneumonia.," Clinical Infectious Diseases, Volume 51, p. S120S125, 01 August.

6 Drakulovic MB, (1999) Supine body position as a risk factor for nosocomial pneumonia in mechanically ventilated patients: A randomised trial. Lancet. Nov 27 1999;354(9193):1851-1858.

\section{HộI CHỨNG HÂ̂U HUYẾT KHỐI SAU ĐIỀU TRỊ NGOẠI KHOA HUYÊT KHỐI TĨNH MẠCH SÂU CHI DƯớI CẤP TÍNH}

\section{TÓM TẮT}

Muc tiêu: Khảo sát tỉ lệ hội chứng hậu huyết khối sau điểu trị ngoai khoa huyết khối tĩnh mach sâu chi dưới. Phương pháp: Nghiên cứu cắt ngang mô tả, đối tượng nghiên cứu là các bệnh nhân huyết khối tĩnh mạch sâu chi dưới đoạn chậu - đùi ở thời điểm 6 tháng sau khi được điều trị ngoại khoa (phẫu thuật lấy huyêt khối, can thiệp nội mạch tiêu sợi huyết) tại khoa Lông ngưoc - Mach máu Bênh viện Đại hoc Y dược Tp Hồ Chí Minh từ tháng 01/2016 đến tháng 12/2020. Kết quả: 65 bênh nhân được điều trị bằng phương pháp phẫu thuậtt (PT) mổ mở, 50 bệnh nhân được điều trị bằng can thiệp nội mạch (CTNM) bơm tiêu sợi huyết tại chố. Tuổi trung bình là 47,3 $\pm 15,0$ tuổi. Độ tuổi thường găp nhất là từ 40 - 60 tuổi chiếm tỉ lể 39,1\%. 98,3\% bệnh nhân có hình ảnh huyết khối hoàn toàn trên chụp cắt lớp vi tính. Hội chứng MayThurner chiếm tỉ lệ 68,7\%. Hội chứng hậu huyết khối sau can thiệp điều trị chiếm tỉ lệ $28,9 \%$, trong đó nhóm PT là $30,2 \%$ và nhóm CTNM là $26,5 \%$. Không ghi nhận sự khác biệt có ý nghĩa thống kê về tỉ lệ hội chứng hậu huyết khối ở 2 nhóm điêu trị với $p=0,72$. Có sự liển quan có ý nghĩa thống kê giữa thời gian khởi phát và hội chứng hậu huyết khối: $B N$ có triệu chứng khởi phát $>7$ ngày có tỉ lệ hội chứng hậu huyết khối cao hơn so với nhóm $<7$ ngày. Bệnh nhẩn có tắc

\footnotetext{
${ }^{1}$ Bệnh viện Đại học Y Dược TP.HCM

Đại hoc Y Dước TP.HCM

Chịu trách nhiệm chính: Lê Phi Long

Email: long.lp@umc.edu.vn

Ngày nhận bài: 5.4.2021

Ngày phản biện khoa học: 24.5.2021

Ngày duyệt bài: 4.6.2021
}

\section{Lê Phi Long ${ }^{1}$, Nguyễn Hoài Nam²}

nghẽn sau 6 tháng điều trị có tỷ lệ hội chứng hậu huyết khối cao hơn so với không có tổn thương tắc nghẽn. Kết luận: Hội chứng hậu huyết khối là một vấn đề cân quan tâm theo dõi sau điều trị huyết khối tĩnh mạch sâu chi dưới cấp tính.

Tư khóa: thuyên tắc tĩnh mạch sâu, hội chứng hậu huyết khối

\section{SUMMARY \\ POST-THROMBOTIC SYNDROME IN PATIENTS AFTER SURGICAL TREATMENT OF LOWER EXTRIMITY DEEP VENOUS THROMBOSIS}

Objectives: To investigate the incidence of postthrombotic syndrome in the patients after sugical treatment of lower extrimity deep venous thrombosis. Methods: Descriptive cross-sectional study in patients who had lower extremity deep vein thrombosis at iliac-femoral segment undergoing surgical treatment (open thrombectomy and endovascular intervention) after in the Thoracic and Vascular department, UMC, Ho Chi Minh City from January 2016 to December 2020. Results: 65 patients were treated with surgical thrombectomy; 50 patients were treated with endovascular intervention. The mean age was $47.3 \pm$ 15.0 years old. It was accounted for $39.1 \%$ patients in the age from 40 to 60 years old. Most of the patients had complete thrombosis on contrast-enhanced computed tomography scan (98.3\%). May-Thurner syndrome accounted for $68.7 \%$. Of $28.9 \%$ patients was confirmed with post-thrombotic syndrome after treatment. This rate in the open thrombectomy group was $30.2 \%$ and the endovascular intervention group was $26.5 \%$. There was no statistically significant difference in the rate of post-thrombotic syndrome in 